\title{
Relationship between BMPN, GSE-6, UWES-9, and EENDEED, a Nine-Item Instrument for Measuring Traditional Workplace and Remote Employee Engagement
}

\author{
Phillip M. Randall1* (D), Franklin M. Lartey ${ }^{(1)}$ \\ ${ }^{1}$ School of Business, Technology, and Health Care Administration, Capella University, Minneapolis, USA \\ ${ }^{2}$ Lartey Research \& Management, Marietta, USA \\ Email: *Phillip.Randall@capella.edu, Franklin@Lartey.net
}

How to cite this paper: Randall, P. M., \& Lartey, F. M. (2022). Relationship between BMPN, GSE-6, UWES-9, and EENDEED, a Nine-Item Instrument for Measuring Traditional Workplace and Remote Employee Engagement. Journal of Human Resource and Sustainability Studies, 10, 30-43. https://doi.org/10.4236/jhrss.2022.101003

Received: January 19, 2022

Accepted: March 4, 2022

Published: March 7, 2022

Copyright $\odot 2022$ by author(s) and Scientific Research Publishing Inc. This work is licensed under the Creative Commons Attribution International License (CC BY 4.0).

http://creativecommons.org/licenses/by/4.0/

\begin{abstract}
EENDEED (Enhanced Engagement Nurtured by Determination, Efficacy, and Exchange Dimensions) is an instrument for measuring the engagement of both remote workers and traditional workplace employees. The purpose of this study was to validate the relationship between EENDEED and its three main theories, namely: 1) self-determination theory, 2) self-efficacy theory, and 3) social-exchange theory. This was done by looking at the relationships between EENDEED and three validated instruments: a) Balanced Measure of Psychological Needs (BMPN), b) General Self-Efficacy scale (GSE-6), and c) Utrecht Work Engagement Scale (UWES-9), that are based respectively on self-determination theory, self-efficacy theory, and social exchange theory. Data were collected from 600 participants in the United States through an online survey. A structural equation model (SEM) was created to ascertain the relationship between EENDEED and the three validated instruments, thus their subtending theories. Findings suggested the existence of positive significant relationships between engagement as measured by EENDEED and BMPN, SGE-6, and UWES-9. Results indicated that for every 1 standard unit increase in the employee engagement as measured by EENDEED, there was an expectation to see an increase in BMPN, GSE-6, and UWES-9 scores by .55, .85, and .82 standard points respectively. This study provided support for external validity of EENDEED and confirmed the existence of positive and significant relationships between engagement of remote employees and traditional office workers as measured by EENDEED and 1) self-determination as measured by BMPN, 2) self-efficacy as measured by SGE-6, and 3) social exchange-based engagement as measured by UWES- 9 .
\end{abstract}




\section{Keywords}

Employee Engagement, Remote Worker, Engagement Instrument, Engagement Scale

\section{Introduction}

Today, employee engagement, per se, is a major and ongoing task for organizations. Whether the employees are working remotely or in a traditional workplace arrangement, engagement remains a continuous challenge for organizational leadership. Engagement of remote workers differs from that of traditional workers. This difference was brought into shape with the advent of the COVID-19 pandemic. For remote workers, Dvorak and Sasaki (2017) reported that more than $50 \%$ the US disengaged employees work remotely. As such, their career development opportunities and organizational visibility are limited (Griswold, 2014; Gajendran et al., 2015) and this consequence is accompanied by increased feelings of isolation (Van Yperen et al., 2014). Whereas tradition workplace workers, although also reported as disengaged, do not report like experiences. Thus, the need for a means to measure the advent and/or extent of engagement among remote workers surfaces as a concomitant requirement among human capital professionals globally.

Further, the COVID-19 pandemic has created a uniquely challenging environment for human capital professional in which they are forced to immediately re-imagine the workplace in order to maintain organizational viability. For example, employees once spent most of their workdays inside brick-and-mortar locations surrounded by coworkers where hourly and daily contact was a part of an every-day experience. The daily routine was planful and predictable in large part. The COVID-19 pandemic experience abruptly thrust the workplace into a quick adjustment to remote work environments. The requirements for self-reliance and self-motivation were accentuated by this disruption resulting in a work environment foreign to most. Albeit, a clarion, if you will, for those responsible for provisioning and enabling a safe and productive work environment. The need to understand the remote worker plight was deemed much needed and the means by which to carry this out was evident.

The purpose of this study was to examine relationship between traditional workplace and remote employee engagement as measured by EENDEED (Enhanced Engagement Nurtured by Determination, Efficacy, and Exchange Dimensions) and three validated instruments namely Balanced Measure of Psychological Needs (BMPN), General Self-Efficacy scale (GSE-6), and Utrecht Work Engagement Scale (UWES-9), based respectively on self-determination theory, self-efficacy theory, and social exchange theory.

The structure and flow of this research study is as follows: 1) Theoretical Foundation; 2) Summary of Measurements Used; 3) Research Methodology; 4) 
Hypothesized Model; 5) Data Analysis; and 6) Results, Discussion, and Conclusion.

\section{Theoretical Perspective and Measurement Instruments}

\subsection{Employee Engagement as Measured by EENDEED}

EENDEED stands for Enhanced Engagement Nurtured by Determination, Efficacy, and Exchange Dimension. It is an instrument developed by Lartey and Randall (2022) that measures traditional workplace employees' and remote employees' engagement at work. As its name suggests, EENDEED is based on three theories namely: Self-Determination theory (SDET), Self-Efficacy theory (SEFT), and Social Exchange theory (SET). The authors posit that together, these three theories capture the essence of employee engagement regardless of their workplace.

For the purposes of this research, the definition of employee engagement is aligned with that of Lartey (2021) suggesting that engagement is:

a two-way relationship between an organization and a worker, in which the organization provides the worker with the environment and conditions to be successful through good leadership and management, and the worker provides the organization with a positive and self-motivated performance leading to the achievement of the organizational mission, vision, purpose, and goals (p. 137).

This definition of engagement suggests the requirement for the employee to use intrinsic forces, which can be explained by the self-efficacy theory and the self-determination theory. It also suggests mutual benefits from the relationship as explained by the social exchange theory.

EENDEED is a two-factor and nine-item instrument used for measuring the engagement of remote employees and traditional office workers. The nine items are statements answered using a five-point Likert scale ranging from (1) Strongly disagree to (5) Strongly agree. The first six items of the scale represent the construct of PERFORMANCE, and the last three represent the construct of SELFRELIANCE. The instrument is presented by Lartey and Randall (2022) as follows:

- At work, my choices express my "true self"

- I look forward to sitting down at my computer to write to others or do my daily work

- I use a lot of expressive symbols in my communication messages, such as :-) or () for "smile", lol for "laugh", etc.

- I am satisfied with the recognition I receive from my supervisor

- At my job, I am doing what really interests me

- I had a career-planning discussion with my manager

- I have control over the quality of my work

- I successfully complete difficult tasks and projects

- I show concern for and interest in the person I am conversing with, in my communication messages 


\subsection{Self Determination Theory (SDET)}

According to the self-determination theory, self-determined individuals are characterized by competence, autonomy, and relatedness (Lartey \& Randall, 2021a). These three constructs constitute the main metavariables of the theory. They must be decomposed into their subtending behaviors to identify the variables that can quantify these constructs.

- Competence: Deci and Ryan (1985) defined competence as the perception of effectiveness in one's capacities. Competence suggests that individuals need to feel a perception of effectiveness when executing a task or completing an activity. For example, when successfully performing an activity, an employee feels capable and competent, thus fulfilling their need for competence. As such, this perception of competence contributes to making employees and remote workers successful in their work. In addition to competence, employees need to have a sense of autonomy when working remotely.

- Autonomy: Autonomy is the need for independence, freedom, self-sufficiency, and self-direction as opposed to a feeling of coercion or constraint (Deci \& Ryan, 2012; Legault, 2017; Guay et al., 2003). It is analogous to being the originator of one's own actions or behavior. Autonomy can be expressed through choices made, such as the choice of swimming as opposed to running for a morning workout.

- Relatedness: Relatedness is the need to feel a connection with others, which also creates a sense of belonging (Deci \& Ryan, 2012; Legault, 2017; Randall et al., 2020). According to Ryan and Deci (2000), relatedness is the need to feel a connection or relation with others. For example, a programmer working on the development of an application feels a sense of relatedness when they know there are other programmers in the team who use the same programming platform. As such, they can exchange experiences and help each other solve issues.

The fulfillment of these three basic psychological needs results in the increase of intrinsic motivation. In turn, it characterizes the employee's self-determination and results in a positive contribution to the employee's level of engagement in the organization (Deci \& Ryan, 2012). Sheldon and Hilpert (2012) proposed the balanced measure of psychological needs (BMPN) as a measure of need satisfaction based on the self-determination theory. This validated 18-item instrument covers the three dimensions of self-determination theory: 1) competence; 2) autonomy; and 3) relatedness.

\subsection{Self-Efficacy Theory (SEFT)}

Bandura $(1977,2007)$ conducted the initial research on self-efficacy. Bandura (2007) stated that self-efficacy refers to the belief that one has the knowledge and skills necessary to organize and execute the tasks needed to produce required results. It is the belief in oneself that one can accomplish the task. Bandura (1997) found that self-efficacy can be affected by factors like vicarious expe- 
rience, verbal persuasion, emotional arousal, and enactive mastery. According to research by Purzer (2011), one's self-efficacy level is the primary indicator that someone will achieve a goal (Lartey \& Randall, 2021b).

Given that the assessment of the self-efficacy construct generally suggests a more elaborate and time-consuming effort, Romppel et al. (2013) developed a six-item short form of the GSE- 6 scale. This reliable, valid instrument can be used in the assessment of GSE, in which a broad confidence in one's ability to deal with demanding situations is preferred. In addition, it enables a more efficient assessment of the self-efficacy construct. The internal consistency for the six-item scale (range alpha $=.79$ to .88 ) was slightly smaller than the value generally observed for the original scale (range alpha $=.75$ to .94$)$. The retest-reliability $(.50$ to .60) was in the range found for the original scale (.47 to .75). The following provides a list of the six questions associated with the GSE short form (Romppel et al., 2013):

- GSE: 1. If someone opposes me, I can find the means to get what I want.

- GSE: 2. It is easy for me to stick to my aims and accomplish my goals.

- GSE: 3. I am confident that I could deal efficiently with the unexpected events.

- GSE: 4. Thanks to my resourcefulness, I know how to handle unforeseen situations.

- GSE: 5. I can remain calm when facing difficulties because I can rely on my coping abilities.

- GSE: 6. No matter what comes my way, I'm usually able to handle it.

\subsection{Social Exchange Theory (SET)}

According to Saks (2006), the SET is a contract or commitment established through continuous interactions between parties in a reciprocal interdependence state. Importantly, Cropanzano and Mitchell (2005) pointed out that the SET is the delineation of reciprocity as it relates to exchange and differentiating forms of reciprocity. Cropanzano and Mitchell (2005) identified three forms of reciprocity: “(a) reciprocity as a transactional pattern of interdependent exchanges, (b) reciprocity as a folk belief, and (c) reciprocity as a moral norm" (p. 876). The key concepts were highlighted and analyzed at a macro level to synthesize ideas and develop a unified conceptual framework to bring more validity and clarity to the SET (Cropanzano \& Mitchell, 2005). Based on the tenets of the SET, Jose and Mampilly (2012) argued that the SET provides a compelling context for rationalizing employee engagement.

A prominent instrument used to measure employee engagement based on the SET is the Utrecht Work Engagement Scale (UWES-9). As explained by Schaufeli et al. (2006), the UWES-9 comprises the dimensions of vigor, dedication, and absorption. The related items of this instrument are presented in what follows.

- SET: 1. I get carried away when I'm working.

- SET: 2. I am immersed in my work.

- SET: 3. I am proud of the work that I do. 
- SET: 4. I feel happy when I am working intensely.

- SET: 5. When I get up in the morning, I feel like going to work.

- SET: 6. My job inspires me.

- SET: 7. I am enthusiastic about my job.

- SET: 8. At my job, I feel strong and vigorous.

- SET: 9. At my work, I feel bursting with energy.

\subsection{Summary of Measurement Instruments}

As explained in what precedes, four main instruments were used in this study. First, EENDEED was used to measure the engagement of remote employees and traditional office workers. The result was the main and only independent variable of the study.

Next, the Balanced Measure of Psychological Needs (BMPN) was selected to measure self-determination, one of the dependent variables (DV). The General Self-Efficacy scale (GSE-6) was selected to measure self-efficacy, the second DV. Finally, the Utrecht Work Engagement instrument (UWES-9) was selected for measuring the social exchange view of engagement, resulting in the third DV.

\section{Methodology and Hypothesized Model}

A structural equation model (SEM) was hypothesized to ascertain the relationship between EENDEED and its three reference theories: 1) self-determination theory; 2) SEFT; and 3) SET. These theories were represented by tools identified to model them, respectively the BMPN, the GSE- 6 short form questionnaire, and the Utrecht Work Engagement Scale (UWES-9). The hypothesized model, presented in Figure 1, uses circles to represent latent variables and rectangles to represent measured variables. Due to the large number of measured variables that require a larger dataset, the underlying items of the constructs of SDET (representing the BMPN score) and SET (representing the UWES-9 score) were represented by the averages of their sub-constructs. Instead of having 18 variables for SDET (made of COMPETENCY, AUTONOMY, and RELATEDNESS), three variables composed of the average of these subtending variables were used. Hence, SDET was represented by COMPET, AUTNM, and RELATD. For SET, three variables were presented instead of the nine that make UWES-9. UWES-9 identifies three main factors (VIGOR, ABSORPTION, and DEDICATION), which are represented by VIGOR, ABSORP, and DEDICAT. The six variables of SEFT were all represented because SGE-6 does not regroup them into sub-constructs.

The hypothesized model seeks to find how much better EENDEED can explain the variances in self-determination represented by BMPN, self-efficacy represented by GSE-6, and social exchange represented by UWES-9. In other words, it seeks to confirm that the data collected from measured variables (rectangles) fit the theoretical model represented in the diagram. To that effect, a SEM was created. SEM is defined by Tabachnick and Fidell (2013) as: "a collection of statistical techniques that allow a set of relationships between one or 


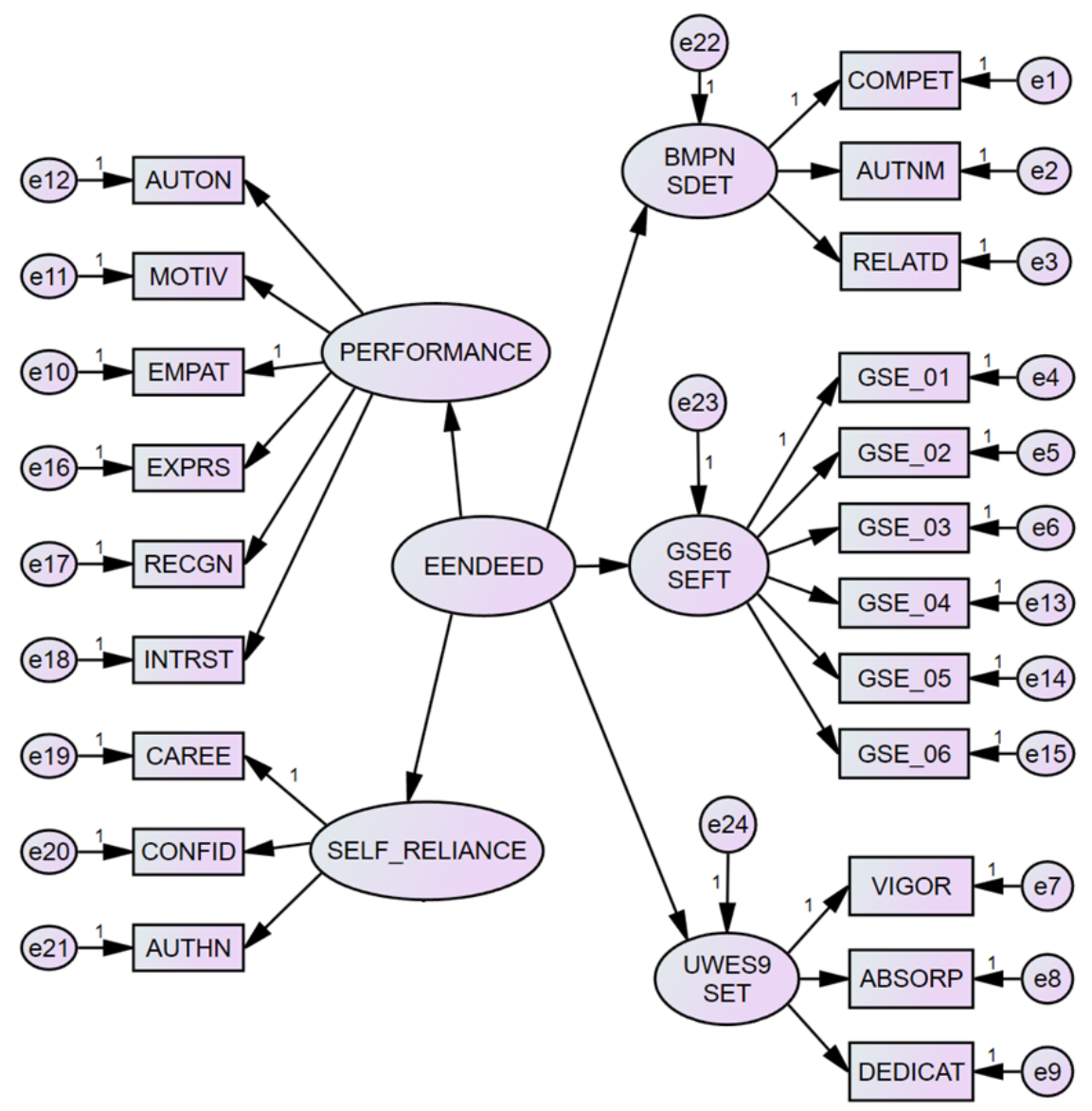

Figure 1. Hypothesized EENDEED model. On this diagram, the absence of a line connecting two variables suggests the absence of interest in a direct relationship between the variables. The rectangles represent measured variables; ovals represent unobserved variables or constructs. Ovals named ex represent error estimates.

more IVs, either continuous or discrete, and one or more DVs, either continuous or discrete to be examined" (p. 681).

The IVs and DVs in SEM can be measured items (variables or indicators) or constructs (latent variables or factors). As represented in the diagram of Figure 2, one IV is named EENDEED, which is an exogenous variable (no arrow pointing toward it). Three IVs are endogenous variables (have arrows pointing toward them).

\section{Data Analysis}

\subsection{Sample Size, Missing Data}

A random number of participants were selected by an online survey firm and a total of 626 participants completed the survey questionnaire. There were no missing data related to the instruments' questions. The gender information had 22 missing values, but that did not have any impact on the 626 cases that had all necessary answers for the study. Overall, $43.8 \%$ of participants were males, $52.4 \%$ were females, .3\% selected "other" as their gender, and 3.5\% did not answer the 
question. The current study did not call for an analysis of demographic data, hence the null effect of the missing data on the overall sample.

\subsection{Reliability and Validity of the Survey Instrument}

Reliability of the survey instrument was assessed using the Cronbach Alpha statistic. A scale reliability analysis performed with IBM SPSS version 24 against the collected data showed a Cronbach Alpha value of .92. This was above the recommended minimum of .70 (Taber, 2018). The internal consistency of the instrument was deemed good; the survey instrument was reliable for conducting the study as presented. Table 1 shows the Cronbach alpha value of each instrument and factors of the instruments.

\subsection{Assumption of SEM}

Several assumptions had to be validated during the process of building the SEM. Tabachnick and Fidell (2013) identified these assumptions as: 1) sample size and missing data; 2) multivariate normality and outliers; 3) linearity; 4) absence of multicollinearity and singularity; and 5) residuals.

\subsubsection{Sample Size Adequacy}

The a-priori sample size calculator for the SEM, as created by Soper (2021), calculated the recommended minimum sample size for the minimum power of .80 . The resulting sample size suggested a minimum of 116 for the model structure and 137 for detecting the required effect given:

1) Medium effect size of .3 where .1 is small effect and .5 large effect size

2) Number of latent or unobserved variables of 4

Table 1. Internal consistencies of the survey instrument and scales included, along with their sub-scales.

\begin{tabular}{cccc}
\hline Instrument or Sub-Scale & Items & Cronbach Alpha & Result \\
\hline EENDEED & 9 & .829 & Pass \\
PERFORMANCE & 6 & .777 & Pass \\
SELF-RELIANCE & 3 & .780 & Pass \\
BMPN & 18 & .661 & Acceptable \\
COMPETENCE & 6 & .634 & Acceptable \\
AUTONOMY & 6 & .665 & Acceptable \\
RELATEDNESS & 6 & .617 & Acceptable \\
SGE-6 & 6 & .835 & Pass \\
UWES-9 & 9 & .912 & Pass \\
ABSORPTION & 2 & .767 & Pass \\
DEDICATION & 4 & .811 & Pass \\
VIGOR & 3 & .845 & Pass \\
SURVEY INSTRUMENT & 42 & .920 & Pass \\
\hline
\end{tabular}


3) Number of observed or measured variables of 21

4) Probability level (p-value, alpha level, or type I error rate) of .05

With the minimum requirement of 137 participants, the current sample size of 626 was sufficient for the SEM. An initial analysis of the collected data showed 26 cases with missing values. These cases were removed from the sample, bringing the size to 600 participants. This number remained above the recommended minimum of 137 .

\subsubsection{Multivariate Normality and Outliers}

Multivariate outliers were assessed using the Mahalanobis statistics, along with the probability that a value from the chi-square distribution with 9 degrees of freedom would be lower than the Mahalanobis distance. The function used was 1 - CDF.CHISQ (MAH_1, 9), where 9 represented the number of measured IVs. Any resulting probability below the alpha level of .05 was considered a multivariate outlier and removed from the sample. This iterative process combined with the identification of univariate outliers. In other words, once a sample was validated to have no more multivariate outliers, a new verification was conducted for univariate outliers using the $z$-score range of -3.29 to +3.29 . If such record was identified and removed, an iterative univariate outlier detection was conducted until stabilization. This was followed by an iterative multivariate outlier detection. After nine iterations, the sample was deemed stable and free from multivariate and univariate outliers. Those iterations resulted in the removal of 30 records, leaving 596 cases for the analysis. The sample was still above the recommended minimum discussed earlier.

The assumption of normality was assessed through the analysis of the skewness and kurtosis of all variables. A descriptive analysis computing the related values showed outputs within the -1 to +1 range, suggesting acceptable normal distributions.

\subsubsection{Linearity}

The presence of linear relationships among pairs of measured variables was validated using the matrix scatter plots. Slopes were confirmed on each pair following a review of the fit lines. As such, the assumption of linearity was deemed fulfilled and no variable needed to be raised to powers.

\subsubsection{Absence of Multicollinearity and Singularity}

The assumption of multicollinearity was validated through the analysis of the tolerance and variance inflation factor (VIF). The collinearity diagnostics showed that all VIFs were below the value of 10 , which is considered critical. Similarly, all tolerance values were greater than .2. In addition, the determinant of the correlation matrix was confirmed to be greater than zero, which is a condition required for SEM to be properly executed.

\subsubsection{Residuals}

Like the determinant of the correlation matrix, the residuals were analyzed after 
the model construction. The frequency distribution of residual covariances was almost symmetrical. With that, the assumption of residual was considered achieved.

\section{Model Estimation and Results}

The SEM was created with Amos version 20 using data from the 596 participants. The model investigated the hypothesis that the proposed EENDEED scale, which is based on three theories (self-determination, self-efficacy, and social exchange), had a significant relationship with validated instruments based on these theories, respectively BMPN, SGE-6, and UWES-9. The model, as shown in Figure 2, specified three paths from EENDEED as a predictor to SDET, SEFT, and SET as outcomes. The resulting model was estimated using maximum likelihood estimation. Although the chi-square for the model was significant, $\chi^{2}(184, \mathrm{~N}=$ 596) $=1317.65, p<.05$, alternative fit indices indicated an acceptable fit to the data $\mathrm{CFI}=.853, \mathrm{NFI}=.828, \mathrm{GFI}=.831$, where a good fit would require each of these indices to be above .9. In addition, the root mean squared error approximation (RMSEA) suggests a poorly specified model if greater than .1 (Field, 2013; Tabachnick \& Fidell, 2013). The RMSEA obtained suggested that the model was acceptable RMSEA $=.09$ even though a good fit would be less than .05 .

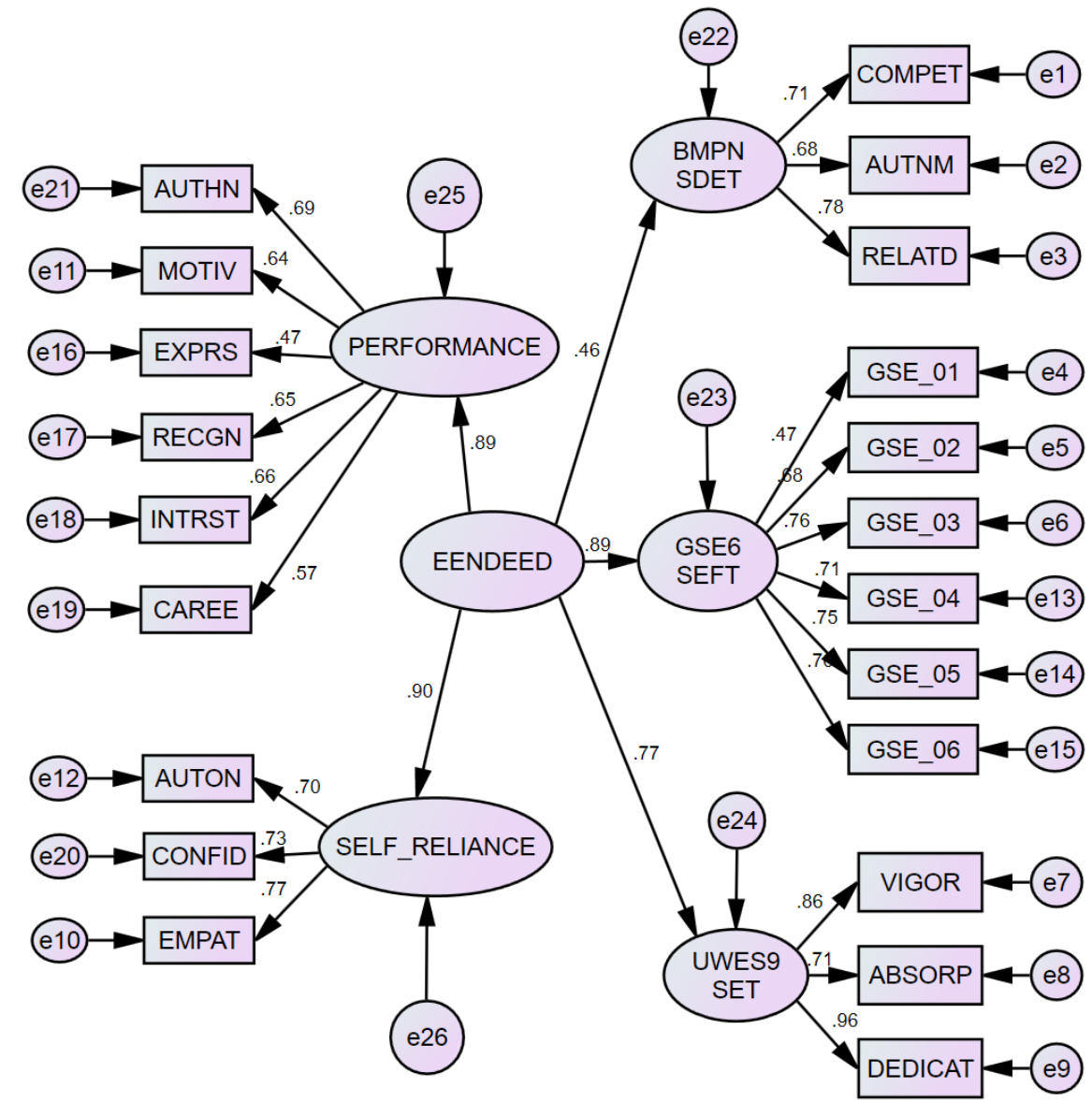

Figure 2. Model with standardized loadings showing the relationships between EENDEED and BMPN (SDET), GSE-6 (SEFT), and UWES-9 (SET). 
The goal of this SEM was not to get the best fit model but to confirm the existence of relationships between EENDEED and the other theories represented by the three instruments considered. Therefore, there was no need for model modification to determine the best fit model.

The results of the SEM in Figure 2 confirmed the relationship between EENDEED and the three DVs. As presented, an increase of EENDEED score by 1 standard deviation value would correspond to an increase in a BMPN (SDET) score by .55 standard deviations. At the same time, SEFT (GSE-6) would increase by .85 standard deviations; SET (UWES-9) would increase by .82 standard deviations.

\section{Discussions, Implications, Limitations, and Future Prospects}

\subsection{Discussions}

This study analyzed the relationship between EENDEED and three other validated instruments namely BMPN, GSE-6, and UWES-9. The aim of the research was to validate the relationship between EENDEED and its subtending theories, namely self-determination, self-efficacy, and social exchange theories. The three selected instruments are each based on the aforementioned theories. The results confirmed the existence of positive and significant relationships between EENDEED and each of the instruments. In other word, an increase in employee engagement as measured by EENDEED would result in an increase in the employee's score as measured by each of the three other instruments. By identifying these relationships, this study also confirmed the concurrent validity of EENDEED. In addition, the high positive correlation of EENDEED with UWES-9, a validated and established instrument measuring employee engagement, confirms the convergent validity of EENDEED as related to employee engagement.

\subsection{Implications}

A remarkable set of human capital challenges and general management problems brought about by the COVID-19 pandemic has become front and center. This situation involves finding ways to adjust the workforce to abruptly shifting work arrangements in terms of just where employees will perform their work and what attendant policies and procedures to develop and administer. The advent of these circumstances has critical and important implications for the employee experience and their associated engagement and productivity. The ability to know the extent of remote worker engagement has catapulted to a top concern. ENDEED is a just-in-time tool to assist organizational leadership in understanding and managing this increasing component of the workforce.

As reported, the number of remote workers is steadily increasing while the levels of workplace engagement have been moving in the opposite direction (Adkins, 2015; Allen et al., 2015; Flores, 2019). As previously explained, more than half the nation's disengaged employees work remotely. Given the paucity of literature on remote worker engagement, the substantiation of this research tool 
and its foundation provides useful resource for management as well as the research community.

In addition to the general and specific management problem, there is also a gap in literature that addresses remote workplace engagement, which made conducting this research study both possible and needed. The research findings included useful information for stakeholders and future scholars researching remote workplace engagement. In this section are implications for social change, theory, and practice.

\subsection{Limitations and Future Prospects}

There were several limitations to this study. Data collection was the source of one limitation. The primary location of the participants was the United States of America, which limits the generalization ability of the study's result to this country. Hence, this constitutes a key opportunity for future research conducted in other countries.

A more specific limitation of this study is associated with the scare amount of research and relevant data related to the remote worker's workplace engagement. To a lesser extent, traditional workplace engagement experience was used to build the framework for the concepts employed in this study. In addition, this study was an online survey, consequently there was little control over the answers provided and there was no opportunity pursued to verify the responses of the participants.

\section{Conclusion}

The current study explored the relationship between traditional workplace and remote employee engagement as measured by EENDEED, and three validated instruments namely BMPN, SGE-6, and UWES-9, based respectively on selfdetermination theory, self-efficacy theory, and social exchange theory. In so doing, this study analyzed how well a measure of EENDEED could predict the other tools' constructs. The results confirmed the existence of positive and significant relationships between engagement as measured by EENDEED and 1) self-determination as measured by BMPN, 2) self-efficacy as measured by SGE-6, and 3) social exchange-based engagement as measured by UWES-9.

This study provided additional external validity to EENDEED and also confirmed its linkage to the three theories (SDET, SEFT, and SET). Its findings suggested that for every 1 standard unit increase in employee engagement as measured by EENDEED, we are expected to see an increase in BMPN, GSE-6, and UWES-9 scores by $.55, .85$, and .82 standard points respectively. By so doing, this study contributed to academia by showing the existence of a relationship between employee engagement and self-determination, self-efficacy, and social exchange. In addition, it confirmed EENDEED as another option for researchers to use in measuring remote employees' and traditional workplace employees' level of engagement. 


\section{Conflicts of Interest}

The authors declare no conflicts of interest regarding the publication of this paper.

\section{References}

Adkins, A. (2015). Majority of U.S. Employees Not Engaged Despite Gains in 2014. http://www.gallup.com/poll/181289/majority-employees-notengaged-despite-gains-201 $\underline{4 . a s p x}$

Allen, T. D., Golden, T. D., \& Shockley, K. M. (2015). How Effective Is Telecommuting? Assessing the Status of Our Scientific Findings. Psychological Science in the Public Interest, 16, 40-68. https://doi.org/10.1177/1529100615593273

Bandura, A. (1977). Self-Efficacy: Toward a Unifying Theory of Behavioral Change. Psychological Review, 84, 191-215. https://doi.org/10.1177/1529100615593273

Bandura, A. (1997). Self-Efficacy: The Exercise of Control. Freeman.

Bandura, A. (2007). Albert Bandura. In G. Lindzey, \& W. M. Runyan (Eds.), A History of Psychology in Autobiography (Vol. 9, pp. 43-75). American Psychological Association. https://doi.org/10.1037/11571-002

Cropanzano, R., \& Mitchell, M. S. (2005). Social Exchange Theory: An Interdisciplinary Review. Journal of Management, 31, 874-900. https://doi.org/10.1177/0149206305279602

Deci, E. L., \& Ryan, R. M. (1985). Intrinsic Motivation and Self-Determination in Human Behavior. Springer. https://doi.org/10.1007/978-1-4899-2271-7

Deci, E. L., \& Ryan, R. M. (2012). Self-Determination Theory. In P. A. M. Van Lange, A. W. Kruglanski, \& E. T. Higgins (Eds.), Handbook of Theories of Social Psychology (pp. 416-436). Sage. https://doi.org/10.4135/9781446249215.n21

Dvorak, N., \& Sasaki, J. (2017). Employees at Home: Less Engaged. http://www.gallup.com/businessjournal/207539/employees-home-lessengaged.aspx/ba nner.html

Field, A. (2013). Discovering Statistics Using IBM SPSS Statistics (4th ed.). SAGE Publications.

Flores, M. F. (2019). Understanding The Challenges of Remote Working and Its Impact to Workers. International Journal of Business Marketing Management, 4, 40-44. http://www.ijbmm.com

Gajendran, R. S., Harrison, D. A., \& Delaney-Klinger, K. (2015). Are Telecommuters Remotely Good Citizens? Unpacking Telecommuting's Effects on Performance via Ideals and Job Resources. Personnel Psychology, 68, 353-393.

https://doi.org/10.1111/peps.12082

Griswold, A. (2014). 3 Strategies for Getting a Promotion When You Work from Home. http://www.businessinsider.com/remote-workers-promotions2014-3

Guay, F., Senécal, C., Gauthier, L., \& Fernet, C. (2003). Predicting Career Indecision: A Self-Determination Theory Perspective. Journal of Counseling Psychology, 50, 165-177. https://doi.org/10.1037/0022-0167.50.2.165

Jose, G., \& Mampilly, S. R. (2012). Satisfaction with HR Practices and Employee Engagement: A Social Exchange Perspective. Journal of Economics and Behavioral Studies, 4, 423-430. https://doi.org/10.22610/jebs.v4i7.343

https://www.researchgate.net/publication/235790288\%27Satisfaction with HR Practi ces and Employee Engagement A Social Exchange Perspective\%27 Journal of Eco 
nomics and Behavioural Studies 7 Vol 4 July 2012

Lartey, F. M. (2021). Impact of Career Planning, Employee Autonomy, and Manager Recognition on Employee Engagement. Journal of Human Resource and Sustainability Studies, 9, 135-158. https://doi.org/10.4236/jhrss.2021.92010

Lartey, F. M., \& Randall, P. M. (2021a). Indicators of Computer-Mediated Communication Affecting Remote Employee Engagement. Journal of Human Resource and Sustainability Studies, 9, 82-92. https://doi.org/10.4236/jhrss.2021.91006

Lartey, F. M., \& Randall, P. M. (2021b). From the Balanced Measure of Psychological Needs (BMPN) to Employee Engagement: Indicators That Matter. International Business Research, 14, 99-107. https://doi.org/10.5539/ibr.v14n6p99

Lartey, F. M., \& Randall, P. M. (2022). Enhanced Engagement Nurtured by Determination, Efficacy, and Exchange Dimensions (EENDEED): A Nine-Item Instrument for Measuring Traditional Workplace and Remote Employee Engagement. International Business Research, 15, 1-23. https://doi.org/10.5539/ibr.v15n2p1

Legault, L. (2017). Self-Determination Theory. In V. Zeigler-Hill \& T. Shackelford (Eds.), Encyclopedia of Personality and Individual Differences. Springer.

https://doi.org/10.1007/978-3-319-28099-8 1162-1

Purzer, S. (2011). The Relationship between Team Discourse, Self-Efficacy, and Individual Achievement: A Sequential Mixed-Methods Study. Journal of Engineering Education, 100, 655-679. https://doi.org/10.1002/j.2168-9830.2011.tb00031.x

Randall, P. M., Lartey, F. M., \& Tate, T. D. (2020). Enterprise Social Media (ESM) Use and Employee Belongingness in US Corporations. Journal of Human Resource Management, 8, 115-124. https://doi.org/10.11648/j.jhrm.201200803.12

Romppel, M., Herrmann-Lingen, C., Wachter, R., Edelmann, F., Düngen, H., Pieske, B., \& Gesine Grande, G. (2013). General Self-Efficacy Scale-Short Form (GSE-6) [Database Record]. APA PsycTests. https://doi.org/10.1037/t69316-000

Ryan, R. M., \& Deci, E. L. (2000). Self-Determination Theory and the Facilitation of Intrinsic Motivation, Social Development, and Well-Being. American Psychologist, 55, 68-78. https://doi.org/10.1037/0003-066X.55.1.68 https://selfdeterminationtheory.org/SDT/documents/2000 RyanDeci SDT.pdf

Saks, A. M. (2006). Antecedents and Consequences of Employee Engagement. Journal of Managerial Psychology, 21, 600-619. https://doi.org/10.1177/0013164405282471

Schaufeli, W. B., Bakker, A. B., \& Salanova, M. (2006). The Measurement of Work Engagement with a Short Questionnaire: A Cross-National Study. Educational and Psychological Measurement, 66, 701-716. https://doi.org/10.1177/0013164405282471

Sheldon, K. M., \& Hilpert, J. C. (2012). The Balanced Measure of Psychological Needs (BMPN) Scale: An Alternative Domain General Measure of Need Satisfaction. Motivation and Emotion, 36, 439-451. https://doi.org/10.1007/s11031-012-9279-4

Soper, D. (2021). A-Priori Sample Size for Structural Equation Models Calculator. https://www.danielsoper.com/statcalc/calculator.aspx?id=89

Tabachnick, B. G., \& Fidell, L. S. (2013). Using Multivariate Statistics (6th ed.). Pearson.

Taber K. T. (2018). The Use of Cronbach's Alpha When Developing and Reporting Research Instruments in Science Education. Research in Science Education, 48, 1273-1296. https://doi.org/10.1007/s11165-016-9602-2

Van Yperen, N. W., Rietzschel, E. F., \& De Jonge, K. M. (2014). Blended Working: For Whom It May (Not) Work. PLoS ONE, 9, Article ID: e102921.

https://doi.org/10.1371/journal.pone.0102921 